\title{
The Role Of Gender In Academic Finance Journals: An Exploratory Study
}

Patricia Hatfield, Ph.D., Bradley University, USA

Shelly Webb, Ph.D., Xavier University, Cincinnati, USA

\begin{abstract}
Since 2001, the proportion of women that have become assistant professors of finance initially increased from less than $20 \%$ to almost $30 \%$ in 2012 before falling slightly in 2013 . On the other hand, women continue to make up less than $20 \%$ of those advancing to associate professor and less than $10 \%$ being promoted to full professor. Research productivity is a primary determinant for promotion, so it appears that many women are not publishing enough or of sufficient quality in order to be promoted. We also find that despite the fact that in 2013 women account for 24\% of associate professors and $10 \%$ of full professors, women still made up less than $8 \%$ of finance journal editors. This is an exploratory study that seeks to understand the role of gender in academic finance and examine some possible reasons, supply side or demand side, why women are under-represented on editorial boards.
\end{abstract}

Keywords: Finance Journals; Editorial Boards; Gender

\section{INTRODUCTION}

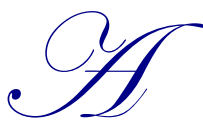

large part of the job for finance professors focuses on research. Faculty members enjoy learning about the financial world and solving financial problems, and they are rewarded in terms of salary and prestige for their research successes. Across a number of disciplines, researchers have investigated the differences in research outcomes for men and women. In fact, they may differ because of demandside reasons (discrimination), supply-side reasons (differences in life choices), or a combination of the two. It is important to know if such differences occur in finance, and if so, why. Beyond the negative implications of discrimination for individuals, the reliance of the field on one gender may affect the types of questions that are being addressed and answered.

The role of women in the business professions has been growing for decades, but small numbers in the finance profession - and especially in higher positions - persevere. A Forbes (2009) article notes that women had only $25 \%$ of the professional Wall Street positions and $10 \%$ of the director and managing director positions before the Great Recession. In spite of these low numbers, the number of women laid off during the recession was equal to the number of men, bringing women's proportional representation further down.

In academics, various studies incorporating gender analysis are scattered throughout different business disciplines. In economics, most research finds that women publish less than their male counterparts (Maske, Durden and Gaynor, 2003; Barbezat, 2006; Broder, 1993; Fish and Gibbons, 1989), though Fender, Taylor and Burke (2005) find no significant impact of gender on the number of publications in the top ten journals. Research in the field of accounting also finds that men publish more than women (Rama, Raghunandan, Logan and Barkman, 1997; Dwyer, 1994; Lehman, 1992). Interestingly, Streuly and Maranto (1994) find that women are more likely to publish in practitioner journals than their male counterparts. More recently, (Metz and Harzing, 2009, 2012) examine how women are represented on editorial boards in management journals and find that women are under-represented given their numbers in the academic profession.

Chan, Chang and Chang (2013) use Google Scholar citations to rank the top 23 finance journals citation counts since it also includes citations on working papers. Normalizing citations to account for age and experience 
differences, they develop a list of the top 50 published authors in finance, of which only one is female. Keys, Owens and Turner (2009) found no significant difference in gender when it comes to publishing in the top 19 finance journals in 1988-2003, though they find that men publish significantly more articles than their female cohorts. A more finely cut analysis that looks at various publishing rates for different levels and types of journals is warranted.

As we note earlier, differences in research productivity may occur for supply-side or demand-side reasons. Supply-side reasons occur if women are more likely to spend more time in household production, at least for some period of time, move to accommodate a spouse's occupational opportunity, or place greater focus on teaching or on more practitioner-oriented work. Demand-side reasons would occur as a result of discrimination. It is possible, for example, that discrimination leads fewer women to select finance as a profession and to face hurdles once they join the academic finance profession. We are reasonably sure that discrimination plays a role in the lack of women in Wall Street positions. According to a Bloomberg article (2013), one particular fraternity has funneled men into highly coveted internships on Wall Street, with almost 3,000 of their members going into finance. According to the article, no other industry employed more than 1800 members. And once women enter the field, they appear to face additional obstacles. A Wall Street Journal survey (2012) of 650 women working in investment banking, securities trading and asset management found that $66 \%$ claimed that their gender make it harder for them to succeed (as opposed to $4 \%$ who felt that their gender made it easier). Finally, a recent study by Brooks, Huang, Kearney and Murray (2014) finds that, when men and women pitched the same entrepreneurial firm using the same slides and the same script, men were $40 \%$ more likely to receive venture capital funding than women.

The problem of gender equity apparently occurs before women enter the workplace: Harvard Business School initiated a two-year strategy in 2011 in order to tackle a problem of gender inequity there (New York Times, 2013). Gender inequity apparently occurred daily in the classrooms, with female students finding it difficult to participate equally in class; with course grades determined largely by participation, females earned lower grades. In addition, female professors were harassed by male students with inappropriate questions and comments on what they were wearing. While the offenses were committed in all business classes, the worst offenses occurred in finance.

We would expect this to affect the number of women who decide to pursue an academic profession in finance as opposed to other fields. The role of women in the business professions has been growing for decades, but small numbers in the finance profession - and especially in higher positions - continues. While it is likely to affect the number of women who enter finance in academics, we do not know if discrimination also has an impact on the publication output of female faculty. A bias may occur if women receive less mentoring regarding their research work or if some editors view women authors differently.

\section{PROFILE OF FINANCE FACULTY 2001-2013}

Data was obtained from The Association to Advance Collegiate Schools of Business (AACSB) for gender breakdown in finance for the assistant, associate and full professor ranks. Figures 1 and 2 show the proportion of female and male professors from 2001 to 2013. The proportion of new assistant professors who are women rises from 2001 through 2007 to almost 30\%, stays about the same through 2012, and falls a bit in 2013. Though an increasing proportion of women become associate professors through 2013, a smaller proportion of women than men progress to associate professor, and there is a substantially smaller proportion of women moving from associate to full professor. By 2013, the proportion of female associate professors remains below the proportion of female assistant professors in 2001 and 2003. If the associate professor data plays out like the assistant professor data, then we should expect to see it rise some over the next couple of years, then stagnate and eventually decline.

AACSB schools require that professors at the assistant level have a terminal degree or have almost completed their terminal degree. Generally after serving seven years as an assistant professor, an individual is either tenured or given a terminal contract. While schools differ in their relative weighting of teaching, research, and service, it is research productivity - in terms of quantity and quality - that is generally the key criterion for promotion. The same is true for promotion from associate to full professor, with quality often of greater importance. 
Thus, the data in figures 1 and 2 suggest that many women are not publishing enough or of sufficient quality in order to receive promotion to associate and full professor.

Figure 1. The Proportion of Women in Finance at all Three Ranks from 2001-2013

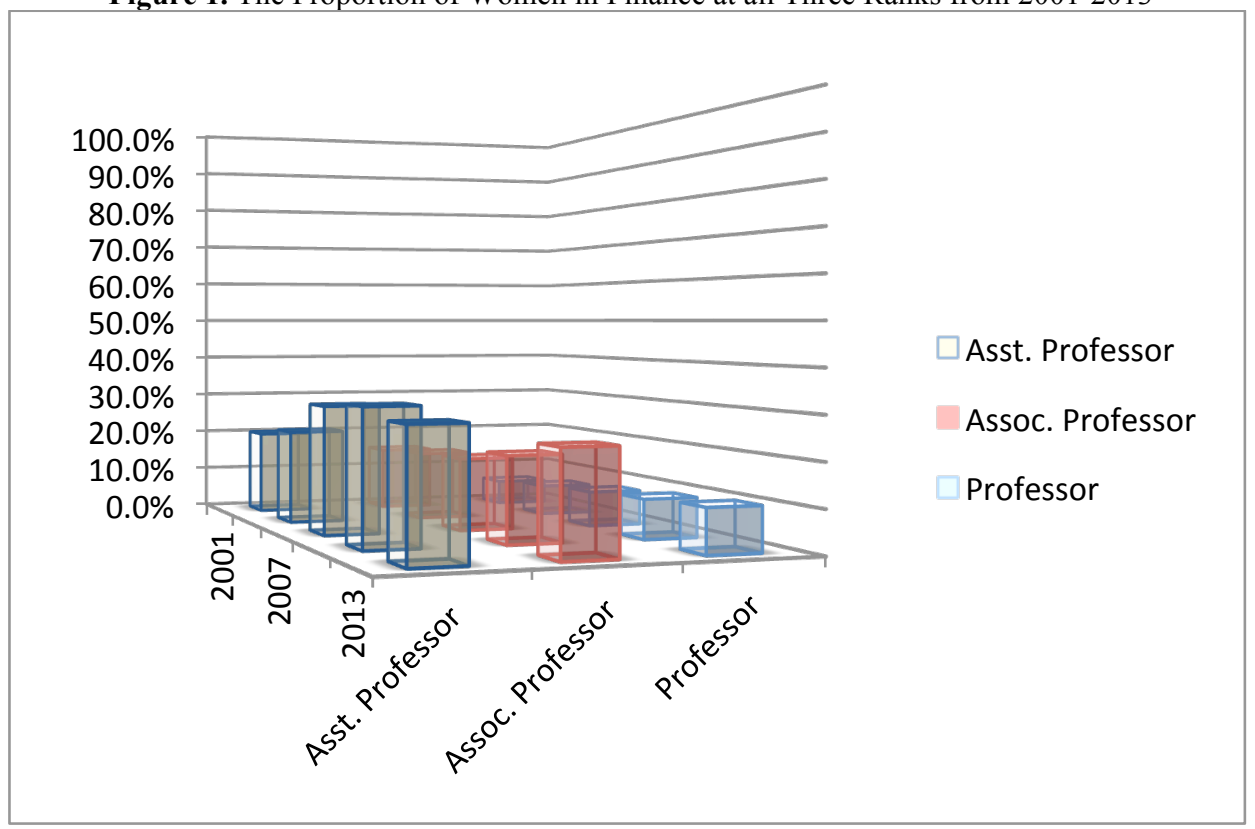

Source: AACSB Annual Salary Survey for 2002-14.

Figure 2. The Proportion of Men in Finance at all Three Ranks from 2001-2013

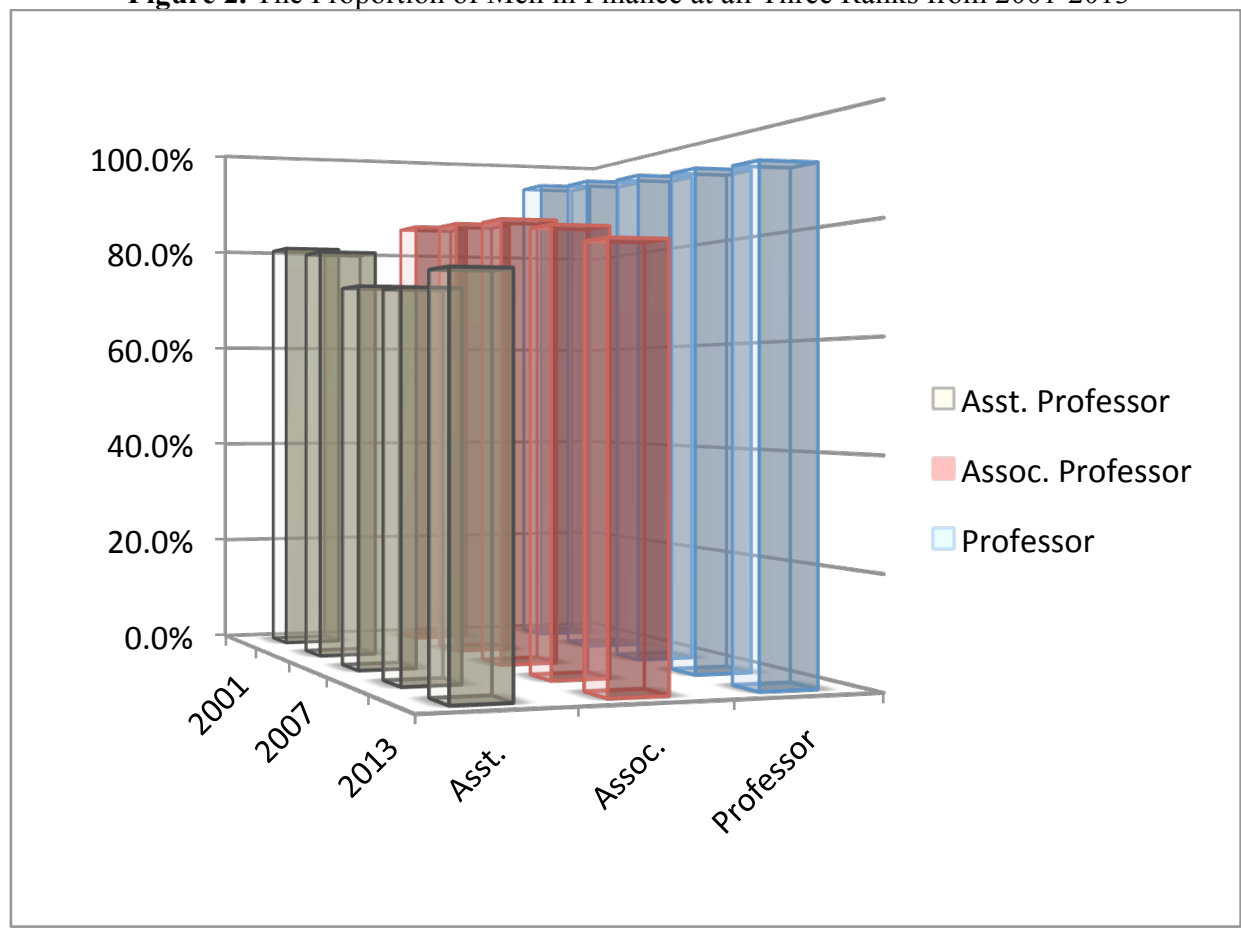

Source: AACSB Annual Salary Survey for 2002-14. 


\section{EDITORIAL BOARDS}

Metz and Harzing $(2009,2012)$ point out that editorial boards have significant influence on the advancement in research in their management fields. Editorial boards control which manuscripts are published, giving them a substantial impact of career trajectories and on the research questions and techniques that are rewarded and subsequently followed. In fact, a number of studies show that men and women may differ somewhat in their research interests and methodologies (Trauth, 2011; Barbezat, 2006; Handeska and Kraimer, 2005; Robinson and Dechant, 1997). Consequently, the gender make-up of editorial boards in finance is likely to influence the research agendas of finance faculty. It will also affect what they teach in the classroom, as a result of both their own research interests and general advances in the field of finance.

The lack of representation for women on editorial boards may also place women at a distinct career disadvantage. There is much networking, exposure to new ideas, and the exchange of information that occurs among editorial board members. In addition, editors may gain recognition by being on a board, raising awareness of their research. As a first step, we need to know the composition of the editorial boards and shed some light on the following questions:

- $\quad$ Are women currently proportionately represented in editorial boards?

- Most journals have three levels of editors. How are women represented at each level?

- Has female representation on editorial boards changed over the years?

- Does the representation of women on editorial boards differ according to the prestige of journals?

- $\quad$ Does the representation of women on editorial boards differ across sub-disciplines?

We cannot answer all these questions here, but we can begin to see what the overall numbers look like.

\section{DATA AND METHODOLOGY}

Data was collected from a random sample of 17 journals chosen from the top 50 journals as ranked by Currie and Pandher (2010). Editorial boards were collected every three years beginning in 1998 and continuing to 2013. While (Metz and Harzing, 2009, 2012) collected data for management journals in 5-year increments, casual observation of finance journals indicates some substantial changes in boards over a three year period. Thus to more closely capture the data accurately, we collected the data every three years. Generally there are 3 levels of editors for journals, so we collected the name and gender of each level of editor. The resulting data base consists of 3,302 data points.

Tables providing descriptive statistics are given below. Table 1 shows the number of female and male editors for the 17 journals in our sample over 1998 through 2013. The sizes of the editorial boards vary considerably, with the largest at 412 editors and the smallest at 63 . The representation of women goes from one to 43, while men account for between 62 and 381 of editors. The mean number of female editors for all levels is 15.47, or $8 \%$ of the total.

Table 1. Descriptive Statistics for 17 Finance Journals, 1998-2013

\begin{tabular}{lcc}
\hline & Female Editors & Male Editors \\
\hline Total Number of Editors & 263 & 3039 \\
Mean & 15.47 & 178.76 \\
Median & 12 & 178 \\
Mode & 11 & 178 \\
Standard Error & 2.70 & 19.71 \\
Standard Deviation & 11.13 & 81.26 \\
Minimum & 1 & 62 \\
Maximum & 43 & 381 \\
\hline
\end{tabular}


Table 2. Males and Females on Editorial Boards by Years

\begin{tabular}{cccccc}
\hline Year & Females & Males & Total & \% Female & \%Male \\
\hline 1998 & 29 & 407 & 436 & $6.7 \%$ & $93.3 \%$ \\
2001 & 34 & 411 & 445 & $7.6 \%$ & $92.4 \%$ \\
2004 & 47 & 546 & 591 & $7.9 \%$ & $92.1 \%$ \\
2007 & 52 & 545 & 597 & $8.7 \%$ & $91.3 \%$ \\
2010 & 52 & 540 & 592 & $8.8 \%$ & $91.2 \%$ \\
2013 & 49 & 590 & 639 & $7.6 \%$ & $92.4 \%$ \\
\hline
\end{tabular}

The number of female editors rises from 29 in 1998 to 52 in 2007, remains there in 2010 and falls in 2013. In proportional terms, it rises from $6.7 \%$ of editors to $8.8 \%$ before dropping back to $7.6 \%$ in 2013 . Male representation remains between $91 \%$ and $94 \%$ throughout the period.

Table 3 provides data on the number of women serving at the three levels of editorship in the journals. The proportion of editors who are women is highest at the lower tier, falling to only $4.3 \%$ at the top; the difference in profiles of men and women may reflect greater influx women in the later years and their fewer years of experience. Their impact on the direction of research is thus likely to be less than indicated by the $8 \%$ of total editorships they occupy during the period.

Table 3. Male and Females on Editorial Boards by Level

\begin{tabular}{|c|c|c|}
\hline Level of Editors & Number and Proportion of Females & Number and Proportion of Males \\
\hline \multirow{2}{*}{ Top Tier } & 8 & 180 \\
\hline & $4.3 \%$ & $95.7 \%$ \\
\hline \multirow{2}{*}{ Middle Tier } & 20 & 314 \\
\hline & $6.0 \%$ & $94.0 \%$ \\
\hline \multirow{2}{*}{ Lower Tier } & 235 & 2545 \\
\hline & $8.4 \%$ & $91.6 \%$ \\
\hline
\end{tabular}

Figure 3 shows the total number of male and female editors by journal. The number of editors for each journal tends to change from one time period. As we noted previously, there is considerable variation between the numbers of editors among journals, and the proportion of female editors varies widely. Thus, women are more proportionately represented in some journals but not in others. Figure 4 shows the same data as in figure 3 but adjusts for the size of the board.

Figure 3. Number of Male and Female Editors of Editorial Boards by Journals

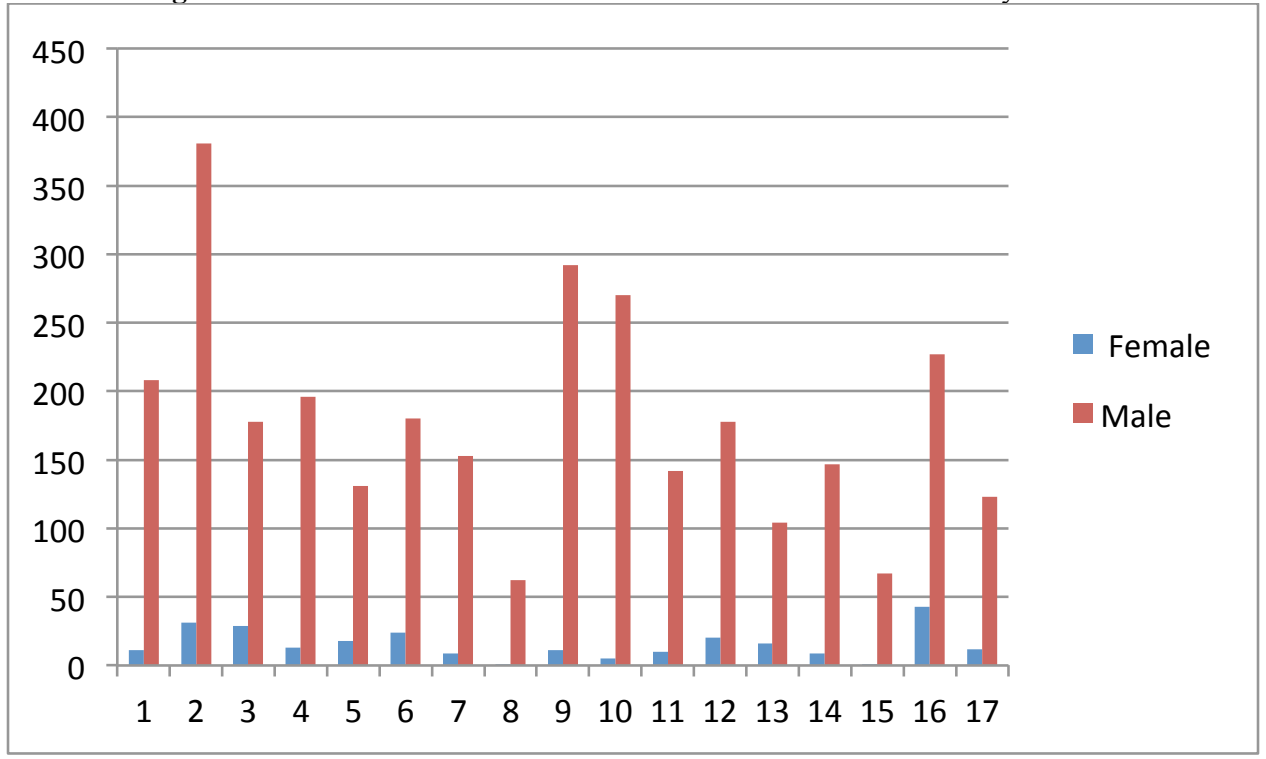


Figure 4. Proportion of Male and Female Editors of Editorial Boards by Journals

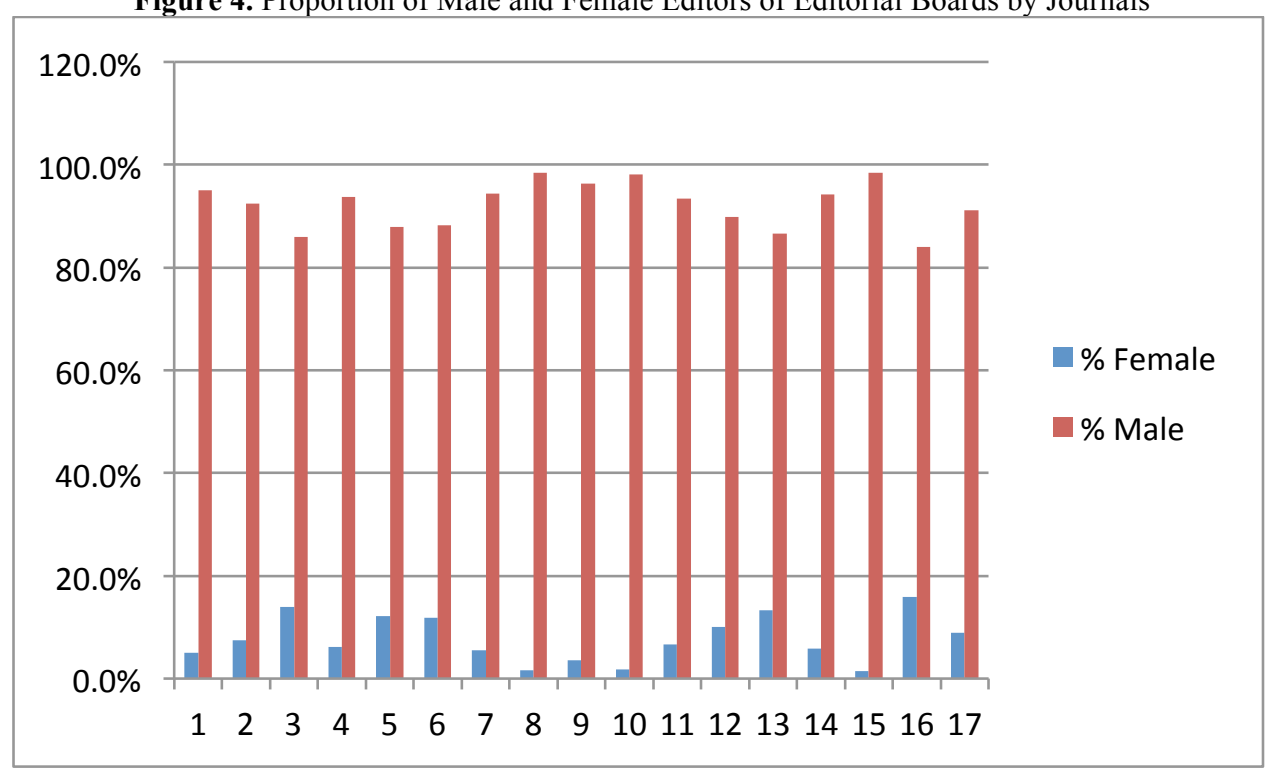

Obtaining an invitation to become an editor generally results from the faculty member's reputation in academic research. It is probably safe to assume that most professors who serve on editorial boards are either associate or full professors. It is somewhat surprising, then, that women in 2013 account for $24 \%$ of associate professors and $10 \%$ of full professors, but less than $8 \%$ of journal editors.

We ran a t-Test for two samples assuming unequal variance to test whether the means of the two samples were different. The first sample is the proportion of female professors at all ranks and the other is the proportion of women on editorial boards for each of our sample years. It is likely that most of the editorial board members are either an associate or full professor. However, by including assistant professors as well, we are recognizing that it is possible that some professors may have received recognition for high quality research before they are tenured and promoted. Thus, we ran the first difference of means test for the two samples of the proportion of female professors at all ranks and the proportion of females on the editorial boards.

Table 4. $t$-Test Two-Sample Assuming Unequal Variances

\begin{tabular}{lcc}
\hline & $\begin{array}{c}\text { Proportion of Female } \\
\text { Professors in Finance }\end{array}$ & $\begin{array}{c}\text { Proportion of Females } \\
\text { on Finance Editorial Boards }\end{array}$ \\
\hline Mean & 0.169914002 & 0.081100044 \\
Variance & 0.00095952 & $3.17452 \mathrm{E}-05$ \\
Observations & 5 & 5 \\
Hypothesized Mean Difference & 0 & \\
Df & 4 & \\
t-stat & 6.307702991 & \\
$\mathbf{P}(\mathbf{T}<=$ t) one-tail & 0.001614944 \\
t Critical one-tail & 2.131846786 & \\
$\mathbf{P}(\mathbf{T}<=t)$ two-tail & 0.003229889 & \\
t Critical two-tail & 2.776445105 & \\
\hline
\end{tabular}

The results indicate that the means of the two samples are significantly different $(p=.003)$. The comparison of means was examined for the five years that we had both proportion of female professors and proportion of women on the editorial board (2001, 2004, 2007, 2010 and 2013). Looking at the means of each sample, it is obvious that females are not proportionately represented on editorial boards. The mean proportion of female professors is twice that of the proportion of women on editorial boards. 
We conduct the difference in means for these two sample groups since it is more likely that associate and full professors make up the majority of the editorial board positions. The results are given in Table 5.

Table 5. t-Test Two-Sample Assuming Unequal Variances

\begin{tabular}{lcc}
\hline & $\begin{array}{c}\text { Proportion of Full and Associate } \\
\text { Female Professors }\end{array}$ & $\begin{array}{c}\text { Proportion of Females on Finance } \\
\text { Editorial Boards }\end{array}$ \\
\hline Mean & 0.12714 & 0.081100044 \\
Variance & 0.000594818 & $3.17452 \mathrm{E}-05$ \\
Observations & 5 & 5 \\
Hypothesized Mean Difference & 0 & 4 \\
Df & 4.112798677 \\
t-stat & 0.007349264 \\
P(T<=t) one-tail & 2.131846786 \\
t Critical one-tail & 0.014698527 \\
P(T<=t) two-tail & 2.776445105 & \\
t Critical two-tail & &
\end{tabular}

The results indicate a significant difference in the means for the two samples $(p=.0146)$. Upon examination of the computed means, the data shows that the proportion of female editors is significantly below the proportion of full and associate female professors when looking at the one tailed test $(\mathrm{p}=.007)$.

What are the recent publication rates for males and females in finance? What about publication rates at the higher level journals? Is this why women are under-represented in journal editorships, or is it something else? Is it true that women do have different interests than most journals editors? If so, this would affect their ability to publish and indicate that their absence from editorships affects the questions that tend to be addressed and techniques used. Here we are providing an initial look at inter-related questions of research productivity, career advancement, and journal leadership.

\section{CONCLUSION}

As a first step to understand the role of women in academic finance, and especially in the pursuit of academic research, we analyze the composition of the journal editorial boards and compare that to the number of women working as finance faculty. We find low representation of women in academic finance, especially in the associate and full professor levels where they make up less than $20 \%$ and $10 \%$ of the totals.

The lack of female research productivity may result from demand-side or supply-side reasons, or some combination of them. Supply-side reasons include the different career choices that women may make, whether they more likely to spend more time in household production, move due to a spouse's career opportunity, place comparatively more effort on teaching and less on the prestige associated with publishing. Demand-side differences occur as a result of discrimination: if women receive less mentoring regarding their research work or if some editors view women authors differently. We add two reasons for reduced female productivity that have to do with the role of editorial boards and are not only supply- or demand-side reasons.

First, we add a hybrid reason that combines the supply and demand sides: female faculty members may differ in their research interests and methodologies from male faculty members, who may make up the preponderance of journal editors. In fact, we know from other academic fields that preferences do differ, and we have shown here that editorial boards are predominantly male. If women are more likely to engage in research that is generally less valued by journal editors, then they will be less likely to publish in their preferred research areas. The comparative disconnect will adversely affect individual careers. Beyond that, the gender make-up of editorial boards in finance is likely to influence the research agendas of finance faculty, and thus the general direction of finance research and what is taught in the finance classroom. And this may have implications for the recruitment of women in the business and academic realms of finance.

Second, the lack of representation for women on editorial boards may also result from supply-side reasons (career choices that result in lower productivity, less active pursuits of editorships) or demand-side reasons 
(discrimination). In either case, it places women in a distinct career disadvantage as a result of the networking, exposure to new ideas, and informal information exchange that occurs among editors.

Notwithstanding, it is clear that women of under-represented in finance journal editorships, and regardless of cause, this is likely $\mathrm{s}$ to have a detrimental impact on their research productivity, the process of acquiring new knowledge in the field, and future gender composition of the profession.

\section{AUTHOR INFORMATION}

Patricia Hatfield, Ph.D., is the Stephens Professor of Risk and Finance in the Foster College of Business at Bradley University. Dr. Hatfield has published research on corporate restructuring activities, capital budgeting, investor risk tolerance, dividend policy and corporate case research. She teaches in the areas of corporate financial theory, capital budgeting, financial statement analysis and personal finance. She actively participates in executive development where she conducts training sessions for management ranging from Fortune 500 firms to mid-sized companies. Patricia Hatfield, Ph.D., (Contact Author), Bradley University, Department of Finance and Quantitative Methods, 1501 W. Bradley Avenue, Foster College of Business, Peoria, IL 61625 USA. Email: Patty@bradley.edu

Shelly Webb, Ph.D., is a Professor of Finance in the Williams College of Business at Xavier University. Her research interests include managerial finance, international finance, and corporate case research. She teaches Executive MBA, MBA, and undergraduate courses in the areas of managerial finance, financial statement analysis, cases in finance, and advanced corporate finance. Shelly Webb, Ph.D., Xavier University, Department of Finance, Williams College of Business, 3800 Victory Parkway, Cincinnati, OH 45207-1213 USA.

Email: Webbs@xavier.edu

\section{ACKNOWLEDGEMENT}

The authors would like to thank Anna Galstyan for her generous assistance in collecting the data for this study.

\section{REFERENCES}

Abelson, M. \& Faux, Z. (2013, December 22). Secret Handshakes Greet Frat Brothers on Wall Street. Retrieved from http://www.bloomberg.com/news/2013-12-23/secret-handshakes-greet-frat-brothers-on-wallstreet.html.

Barbezat, D.A. (2006). Gender Differences in Research Patterns Among PhD Economists. Journal of Economic Education, 37, Summer, 359-375.

Broder, I. E. (1993). Professional Achievements and Gender Differences Among American Economists. Economic Inquiry, 31, January, 116-27.

Brooks, A.W., Huang, L., Kearney S. W. \& Murray, F. E. (2014), Investors Prefer Entrepreneurial Ventures Pitched by Attractive Men. Proceedings of the National Academy of Sciences, March.

Chan, K. C., Chang, C. H. \& Chang, Y. (2013). Ranking of Finance Journals: Some Google Scholar Citation Perspectives. Journal of Empirical Finance, 21, March, 241-250.

Chinwala, Y. (2012, June 11) Women in Finance are Cold on Quotas. Retrieved from http://online.wsj.com/news/articles/SB10001424052702303768104577458210879222988.

Currie, R. \& Pandher, G. (2011). Finance Journal Rankings and Tiers: An Active Scholar Assessment Methodology. Journal of Banking and Finance, 35(1), 7.

Dwyer, P. D. (1994). Gender Differences in the Scholarly Activities of Accounting Academics: An Empirical Investigation. Issues in Accounting Education, 9, Fall, 231-242.

Fender, B. F., Taylor, S. W. \& Burke, K. G. (2005). Making the Big Leagues: Factors Contributing to Publication in Elite Economics Journals. Atlantic Economic Journal, 33, 93-103.

Fish, M. \& Gibbons, J. D. (1989). A Comparison of the Publications of Female and Male Economists. Journal of Economic Education, 20, Winter, 93-105.

Handeska, K. \& Kraimer, M. (2005). Women's Perceptions of Organizational Culture, Work Attitudes and RoleModeling Behaviors. Journal of Managerial Issues, 17, Winter, 461-478.

Harzing, A. (2013). Journal Quality List, $50^{\text {th }}$ edition, July. 
Hitt, M. A. (2009). Editorial Judgements, Quality Scholarship, and the Academy of Management's Journals. Organizational Research Methods, 12, February, 253-258.

Kantor, J. (2013). Harvard Business School Case Study: Gender Equity, New York Times, September 7.

Keys, P. Y., Owens, W. L. \& Turner, P. A. (2009). A Gender Analysis of Productivity and Quality in Finance Research. Journal of Financial Education, Spring, 66-79.

Lehman, C. R. (1992). Letter From the Chair, Newsletter of the Gender Issues in Accounting. May.1.

Maske, K. L., Durden, G. C. \& Gaynor, P. E. (2003). Determinants of Scholarly Productivity Among Male and Female Economists. Economic Inquiry, 41, October, 555-64.

Metz, I. \& Harzing, A. (2009). Gender Diversity in Editorial Boards of Management Journals. Academy of Management Learning and Education, 8, 540-557.

Metz, I. \& Harzing, A. (2012). An Update of Gender Diversity in Editorial Boards: A Longitudinal Study of Management Journals. Personnel Review, 41, May, 283-300.

Raghaven, A. (2009, February 26). Terminated: Why the Women of Wall Street are Disappearing. Retrieved from http://www.forbes.com/forbes/2009/0316/072 terminated women.html.

Rama, D. V., Raghunandan, K., Logan, L. B. \& Barkman, B. V. (1997). Gender Differences in Publications by Promoted Faculty. Issues in Accounting Education, 12, Fall, 353-365.

Robinson, G. \& Dechant, K. (1997). Building and Executive Case for Diversity. Academy of Management Executive, 11, August, 21-31.

Streuly, C. A., \& Maranto, C. L. (1994). Accounting Faculty Research and Productivity and Citations: Are There Gender Differences? Issues in Accounting Education, 9, Fall, 247-258.

Trauth, E. (2011). What Can We Learn from Gender Research? Seven Lessons for Business Research Methods. Electronic Journal of Business Research Methods, 9, January, 1-9. 
NOTES 